\title{
Mice divergently selected for high and low basal metabolic rates evolved different cell size and organ mass
}

\author{
S. MACIAK*, E. BONDA-OSTASZEWSKA*, M. CZARNOŁESKI†, M. KONARZEWSKI* \\ \& J. KOZŁOWSKI† \\ *Institute of Biology, University of Biatystok, Białystok, Poland \\ $\uparrow$ Institute of Environmental Sciences, Jagiellonian University, Kraków, Poland
}

\author{
Keywords: \\ cell size evolution; \\ karyoplasmic ratio; \\ metabolic rate; \\ mice; \\ selection.
}

\begin{abstract}
Evolution of metabolic rates of multicellular organisms is hypothesized to reflect the evolution of their cell architecture. This is likely to stem from a tight link between the sizes of cells and nuclei, which are expected to be inversely related to cell metabolism. Here, we analysed basal metabolic rate (BMR), internal organ masses and the cell/nucleus size in different tissues of laboratory mice divergently selected for high/low mass-corrected BMR and four random-bred mouse lines. Random-bred lines had intermediate levels of BMR as compared to low- and high-BMR lines. Yet, this pattern was only partly consistent with the between-line differences in cell/nucleus sizes. Erythrocytes and skin epithelium cells were smaller in the high-BMR line than in other lines, but the cells of low-BMR and random-bred mice were similar in size. On the other hand, the size of hepatocytes, kidney proximal tubule cells and duodenum enterocytes were larger in high-BMR mice than other lines. All cell and nucleus sizes were positively correlated, which supports the role of the nucleus in cell size regulation. Our results suggest that the evolution of high BMR involves a reduction in cell size in specialized tissues, whose functions are primarily dictated by surface-to-volume ratios, such as erythrocytes. High BMR may, however, also incur an increase in cell size in tissues with an intense transcription and translation, such as hepatocytes.
\end{abstract}

\section{Introduction}

Intensity at which a multicellular body utilizes energy obtained from food, called the rate of metabolism, is a sum of energies expended by its cells. Organisms have evolved dramatic differences in metabolic rates, and undoubtedly the major determinant of this variance is body mass. Given that body mass evolves through a combination of changes in cell number and cell size (Falconer et al., 1978; Stevenson et al., 1995; Kozłowski et al., 2010), a mass scaling of metabolic rate tells us about coevolution between cellular metabolism and body mass. Most often, we observe a decelerating increase in metabolic rate with body mass (e.g. Glazier,

Correspondence: Sebastian Maciak, Virginia Bioinformatics Institute, VirginiaTech, 1015 Life Science Circle, Blacksburg, VA 24061, USA. Tel.: +1 540-231-3125; fax: +1 540-231-2606; e-mail:maciaks@vbi.vt.edu
2005, 2010; Makarieva et al., 2008; McNab, 2008), which suggests that large organisms usually evolve cells that are metabolically less active (per cytoplasm unit) than the cells of small organisms. The mass scaling of metabolic rate differs between taxonomic groups (e.g. Glazier, 2005, 2010; White et al., 2007), and it may even evolve under experimental conditions (Czarnołęski et al., 2008), indicating that organisms evolve differential coupling between their cellular metabolism and body mass. Statistical models that we fit to data on metabolic rate and body mass do not capture the entire variance in metabolic rate: equally large organisms still differ many-fold in their metabolic rates (Isaac \& Carbone, 2010; White et al., 2011). Thus, apparently, the evolutions of cellular metabolism and body mass can be decoupled from each other.

Despite long and hot debates on scaling laws in metabolism (Kleiber, 1947; Heusner, 1982; Kozłowski 
et al., 2003; Brown et al., 2004; Glazier, 2005; Maciak et al., 2011; White et al., 2011), the origin and evolutionary significance of mass scaling of metabolic rates still remain unclear. Emerging evidence documented links between variation in cell size and metabolic rate scaling (Chown et al., 2007; Maciak et al., 2011; Starostová et al., 2013); however, most of recently proposed explanations of allometries of metabolic rate such as metabolic theory of ecology (Brown et al., 2004), metabolic level boundaries (Glazier, 2005, 2010), dynamic energy budgets (Kooijman, 2010) still do not consider cell size as a potential factor affecting metabolic rates. According to Kozłowski et al. (2003) (hereafter, cell metabolism hypothesis, CMH), nonlinear changes of cell surface area with cell volume and costs associated with the maintenance of plasma membranes should lead to an inverse relation between cell size and cell mass-specific metabolic rates. Following the assumption that cell metabolic rate is completely defined by the surface-to-volume ratio, $\mathrm{CMH}$ predicts that organisms built from smaller cells should have higher metabolic rates (with allometric slope close to 1) than those of comparable body size, but built of larger ones (slope 2/3). However, assuming realistically that maintenance of membranes' gradients reaches roughly $20 \%$ of basic metabolic costs (Buttgereit \& Brand, 1995; Hochachka et al., 2003), difference between slope's values predicted by CMH must be less dramatic. What is more, we still do not know how well $\mathrm{CMH}$ can account for mass-independent variance in metabolic rates.

Here, we study metabolic rates and the size of five cell types in mice artificially selected for either high or low basal metabolic rate (BMR), while keeping body mass unaffected. Previous studies showed that this selection resulted in a genetically driven, $40 \%$ divergence in BMR, along with a positive sizable correlated responses in food consumption, masses of metabolically active internal organs (liver, kidney, heart and small intestine) and voluntary activity (Książek et al., 2004; Brzęk et al., 2007; summarized in Konarzewski \& Książek, 2013). Mice from this selection experiment offer a unique opportunity to test hypotheses on coevolutionary changes in cell size and metabolism, which are decoupled from the evolution of body mass. Our primary aim is to test whether selection-driven divergence in BMR was associated with changes in cell size. Given predictions of $\mathrm{CMH}$, we expect to find an inverse correlation between cell size and body mass-corrected BMR. In addition, we examined associations between cell size and nucleus size. Several lines of evidence suggest existence of a positive association between the size of a cell and the size of its nucleus, which is hypothesized to reflect links between transcription activity and nucleus size (Cavalier-Smith, 2005). A nucleus-to-cell size ratio (so-called karyoplasmic ratio) seems to play a critical role in cell development (and so cell size) and in physiological processes in cytoplasm (Wells, 2002; Jorgensen \& Tyers, 2004). Finally, we tested the hypothesis that different cell types evolve their size in concert (Kozłowski et al., 2010). Note that the majority of studies that examined links between metabolic rates and cell size focused on one cell type, mainly erythrocytes, assuming a strong correlation with cell sizes of other tissues (e.g. Gregory, 2001; Maciak et al., 2011). Although this assumption seems to be supported by some data (Kozłowski et al., 2010), prevalence of this correlation still remains to be tested.

\section{Materials and methods}

\section{Study animals}

We analysed BMR, organ mass, cell size and basic haematological parameters in 20-week-old males of laboratory mice (Mus musculus) of six genetic lines. Two of those lines were subjected to divergent nonreplicated artificial selection either towards high (high BMR) or low (low BMR) body mass-corrected BMR (for details see Książek et al., 2004). The other four lines were randomly bred as a part of a concurrent artificial selection experiment (Gębczyński \& Konarzewski, 2009, 2011).

We used 30 mice from the 34th generation of highBMR and low-BMR lines (15 from each line) and 40 mice from the 10th generation of randomly bred lines (10 from each line). Prior to our study, animals were kept individually in plastic cages at $32 \pm 0.1{ }^{\circ} \mathrm{C}$ and $12 \mathrm{~d}: 12 \mathrm{n}$ photoperiod with unlimited access to food (murine laboratory chow, Labofeed, Poland) and water. All procedures were approved by the local ethical committee in Białystok (approval \#22/2009).

\section{Metabolic rate measurements}

Metabolic measurements were taken between 8:00 am and 8:00 pm on animals fasted for $6 \mathrm{~h}$. BMR was measured following the procedure of Książek et al. (2004). Briefly, we used a positive-pressure open-circuit respirometry system with dried and warmed atmospheric air pushed through the system. The airstream was divided into four streams, including one baseline, each fed to a separate mass flow controller (Sierra Instruments, Monterey, CA, USA or ERG-1000, Warsaw, Poland) forced at the rate of $400 \mathrm{~mL} \mathrm{~min}^{-1}$. The system sequentially monitored metabolic rates of mice placed individually in three $350 \mathrm{~cm}^{3}$ chambers. The chambers were submerged in a water bath set at $32 \pm 0.1{ }^{\circ} \mathrm{C}$ (thermoneutral zone for mice). The airstream from chambers was directed to a computer-controlled channel multiplexer, a part of a Sable Systems TR-1 oxygen analyzer (Henderson, NV, USA). The air was sampled at the rate of $75 \mathrm{~mL} \mathrm{~min}^{-1}$, and prior to passing through an oxygen sensor (S-3A/I Applied Electrochemistry, Pittsburgh, 
PA, USA), it was scrubbed off $\mathrm{CO}_{2}$ (Carboabsorb AS, BDH Laboratory Supplies, Lutterworth, UK) and moisture (Drierite, Drierite Co.LTD, Xenia, OH, USA). Each metabolic measurement trial lasted $3 \mathrm{~h}$, and oxygen concentrations in each chamber were recorded every second for $2 \mathrm{~h}$. We defined BMR $\left(\mathrm{mL} \mathrm{O}_{2} \mathrm{~h}^{-1} \pm 0.0013\right)$ as the lowest rate of oxygen consumption that did not change for at least $4 \mathrm{~min}$ by more than $0.01 \%$. Metabolic data were analysed with a Sable System DATACAN V software. We calculated oxygen consumption rates using the formula (4a) of Withers (1977).

\section{Haematology and cell size measurements}

After metabolic measurements, animals were weighed $(\mathrm{g} \pm 0.01)$ and decapitated. Immediately after decapitation, blood samples were taken directly from the heart to measure haematocrit (Hct\%), total haemoglobin content $\left(\mathrm{Hb} \mathrm{g} \mathrm{dL}^{-1}\right)$, and to prepare blood smears. The smears were fixed and stained with methanol Wright-Giemsa modified solution (Sigma-Aldrich, Inc., St. Louis, Louis, MO, USA). Mice were dissected to obtain liver, kidney and duodenum for histological analyses. The liver and kidney were weighed $(\mathrm{g} \pm 0.01)$. Skin tissue samples were taken from the dorsal side of mice. Tissue samples were fixed for 2 weeks in $4 \%$ formaldehyde, then dehydrated in ethanol and xylene, embedded in paraffin and sliced to $5 \mu \mathrm{m}$ sections (semi-automated rotary microtome RM 2245, Leica Biosystems, Nussloch, Germany) to prepare histological slides. The slides were stained with haematoxylin and eosin.

Blood smears and histological slides were digitized under the microscope (magnification 1000×; DM 1000, Leica Biosystems, Nussloch, Germany) with a help of Leica ICC50 camera. Digital image analysis software (MultiScan Base 14.02; CSS Ltd., Warsaw, Poland) was used to measure the size of five different types of cells. We randomly chose fifty erythrocytes per blood smear and measured their diameter $(\mu \mathrm{m})$. Assuming a circular shape of lying-flat blood cells, the diameter was used to calculate the erythrocytes' area $\left(\mu \mathrm{m}^{2}\right)$. We measured the cross-sectional area $\left(\mu \mathrm{m}^{2}\right)$ of hepatocytes in liver, proximal tubule cells in kidney, enterocytes in duodenum and skin epithelium cells (30 randomly chosen cells of each tissue per mouse) and the cross-sectional area of cell nuclei $\left(\mu \mathrm{m}^{2}\right)$ by outlining the edges of cells and nuclei (areas were calculated automatically in all cases with algorithm used by MultiScan software). Data on cell and nucleus sizes were used to calculate a karyoplasmic ratio of cells (nucleus area/cell area). This index measures the relative size of nuclei. Tissue-specific mean values of cell size, nucleus size and karyoplasmic ratio were used in our hypothesis testing as characteristics of individual mice.

\section{Hypothesis testing}

\section{Analysis of effects of selection in the absence of replicated selection lines}

Phenotypic differences between selection lines can indicate the genuine effect of divergent selection or effects of genetic drift. The method of choice for discriminating between these two possibilities is to maintain several replicated selection lines along with several control lines and test the effect of selection by a 'mixed-model' nested analysis of variance (for review see Swallow et al., 2009). Despite undeniable efficacy of replication as the means for controlling random effects, many selection experiments, including ours, did not include a replicate sample (e.g. Koch \& Britton, 2001; Książek et al., 2004; Wislöff et al., 2005). The major reason for the lack of replication in such studies is time and resource limitation. For example, in our case, it takes 4-6 weeks to collect the measurements on the sufficient number of animals to carry out the selection in just one pair of selected lines. The maintenance of another 3-4 replicates is therefore unfeasible. This is most likely why our divergent selection on BMR is the only existing one of this kind, and even though it is not fully satisfactory from a methodological standpoint, it has already provided a wealth of information (for review see Konarzewski \& Książek, 2013).

To account for the shortcomings incurred by the lack of replication in our selection experiment, we applied the procedure suggested by Henderson (1997). We first calculated a magnitude of phenotypic separation $\left(d_{x}\right)$ of high-BMR and low-BMR mouse lines for each trait. Values of $d_{x}$ were then expressed as multiples of intraline phenotypic standard deviations, following methods of Konarzewski et al. (2005). They were then compared with the magnitude of interline separation expected under genetic drift and sampling error alone (thereafter $\left.d_{\text {drift }}\right)$, that is, in the absence of genetic correlation between the primary selected trait (BMR) and other analysed traits. Values of $d_{x}$ falling within the $95 \%$ confidence intervals of $d_{\text {drift }}$ cannot therefore be ascribed to the effect of selection. Conversely, values of $d_{x}$ exceeding of $d_{\text {drift }}$ are indicative of genetic correlations, because interline differences resulting from genetic drift should be smaller than those due to correlated response to selection on BMR (Henderson, 1997; Konarzewski et al., 2005).

To estimate $d_{\text {drift }}$, we used equation (16) in HenderSon (1997), $d_{\text {drift }} \cong 2 \sqrt{h_{x}^{2} F+1 / n}$

where $F$ is the coefficient of inbreeding, $h_{x}^{2}$ is the coefficient of heritability of an analysed trait, and $n$ is the number of families subjected to selection (22 in the case of our high-BMR and low-BMR groups). The coefficient of inbreeding $F$ of our selection mice was estimated for the 33rd generation (0.227) using Falconer 8 Mackay's (1996) method. Values of $h_{x}^{2}$ were assumed to be equal to 0.38 for BMR (Konarzewski et al., 2005), 
0.40 for body mass (Konarzewski, unpublished data), 0.36 for liver mass (Jones et al., 1992) and 0.40 for kidney mass (Schlager, 1968). Heritability of other analysed traits remains unknown for mice (Konarzewski et al., 2005); therefore, we assumed that it was fairly low $\left(h^{2}=0.1\right)$.

\section{Analysis of patterns of variation across all six mouse lines}

To further extend the scope of our study, we analysed variation in studied traits in a data set consisting of all six mouse lines: two lines divergently selected for BMR and the other four lines randomly bred as a part of a concurrent artificial selection experiment (Gębczyński \& Konarzewski, 2009, 2011). It is important to note that although all those lines originated from an outbred Swiss-Webster strain, they were not derived from the same base population. Therefore, the randomly bred lines are not considered here as a genuine control with respect to the lines divergently selected for BMR. However, with this restriction in mind, it is still informative to carry out between-strain comparisons and infer much in the same way as with the use of comparative methods applied to different populations or species, but being free from the effect of phylogenetic inertia confounding between-species comparisons (Harvey $\&$ Pagel, 1991).

\section{Statistical analyses}

Variation in BMR, body mass, organ masses, haematological parameters, cell sizes and karyoplasmic ratios across all six lines was analysed with general linear model (GLM, SAS 9.1, Cary, NC, USA, 1996). The d.f. for the numerator of the $F$ test was two and accounted for three fixed levels of variation (low-BMR, high-BMR and random-bred lines), whereas d.f. for denominator was three and corresponded to random variation between four nonselected lines. We used body mass as a covariate in all GLM models, except models for the haematological parameters and karyoplasmic ratios. Post hoc comparisons were analysed with a Tukey's test.

To examine whether cell sizes in different tissues change in concert, we calculated line-specific means of cell size in each tissue. Then we carried out a correlation analysis of means cell size in one tissue with mean cell sizes in other tissues. To examine relationships between cell size and nucleus size, we calculated linespecific mean of nucleus size and correlated them with the line-specific means of cell size.

All statistical analyses were performed on raw data as they had normal distributions.

\section{Results}

Table 1 reports values of separation coefficients $\left(d_{x}\right)$, which quantify the relative effect of selection on differentiation of phenotypes between high-BMR and low-BMR lines. The separation coefficients were calculated for eight traits that according to our GLM (Table 1) diverged significantly in these two line types. All values of separation coefficient exceeded an upper limit of $95 \%$ confidence intervals for $d_{\text {drift }}$ which indicates a dominant role of selection in differentiation of these traits in high-BMR and low-BMR mice.

Results of GLM (Table 1) showed that the three types of lines (high BMR, low BMR and random bred) did not differ significantly with respect to body mass (Fig. la). Yet, we detected sizable differences in body mass-corrected BMR, with four random-bred lines having intermediate levels of BMR as compared to lowBMR and high-BMR lines (Fig. lb). If this pattern were predominantly driven by the between-line differences in masses of metabolically active organs contributing to BMR, one would expect to find similar patterns emerging from a comparison of the masses of these organs. This was only partially supported by the GLM analyses, as mice of random-bred lines had similar liver mass to high-BMR mice, but still higher than that of low-BMR mice (Fig. 1c). On the other hand, random-bred mice had similar kidney mass to low-BMR mice but lower than that of high-BMR mice (Fig. 1d).

If the CMH holds, one would expect a close inverse match between the pattern of between-line variation in BMR (Fig. 1b) and cell sizes. In case of erythrocytes and skin epithelium cells, this inverse match was only partial, as these cell types were indeed smaller in highBMR line than in other lines, but the cells of low-BMR and random-bred mice were similar in size (Fig. 2a and $2 \mathrm{~b}$, respectively). Moreover, in contrast to the $\mathrm{CMH}$ predictions, the size of hepatocytes, kidney proximal tubule cells and duodenum enterocytes was larger in high-BMR mice than in mice of the other lines (Fig. 2c-e).

Although we found a clear pattern of between-line type differences in erythrocyte size, it did not correspond with the differences in haemoglobin level. The amount of haemoglobin was similar between BMRselected lines and was considerably higher in randombred mice (Table 1). We did not find between-line differences in haematocrit.

Apart from the sizes of erythrocytes and skin cells $(r=0.74, P=0.09)$, the sizes of all other cells were significantly correlated with each other (Table 2). A positive size correlation existed between liver hepatocytes, duodenum enterocytes and kidney proximal tubule cells ( $r$ ranged from 0.93 to 0.98 ). The sizes of hepatocytes, proximal tubule cells and enterocytes were negatively correlated with the sizes of erythrocytes and skin epithelium cells ( $r$ ranged from -0.85 to -0.92 ).

All nucleated cell types had their size positively correlated with the size of nucleus ( $r$ ranged from 0.97 to 0.99; Table 2). The karyoplasmic ratio of hepatocytes in low-BMR mice was about $10 \%$ lower in comparison with high-BMR and random-bred groups (Table 1). The 


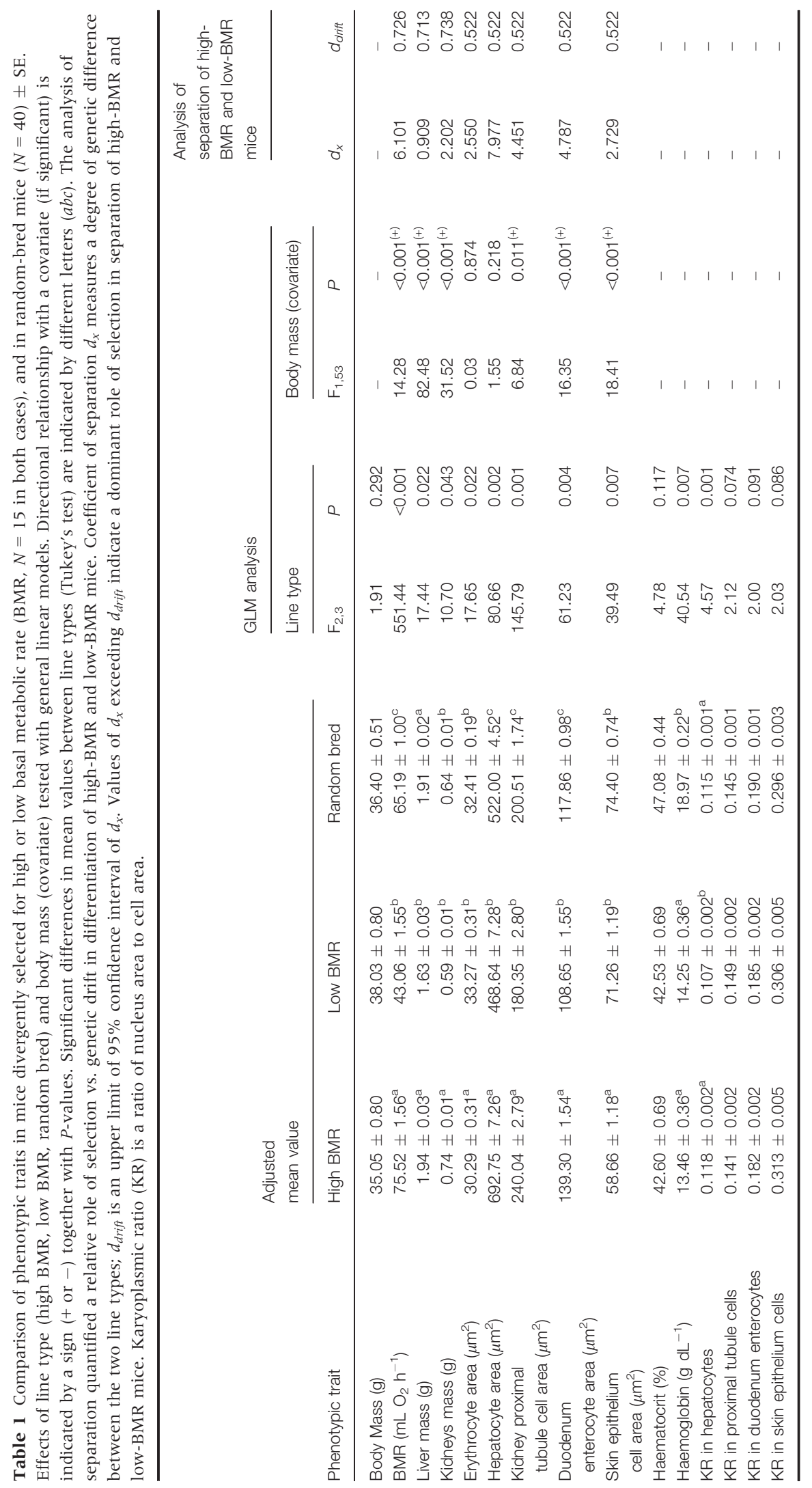

(C) 2014 THE AUTHORS, J EVOL, BIOL, 27 (2014) 478-487 JOURNAL OF EVOLUTIONARY BIOLOGY @ 2014 EUROPEAN SOCIETY FOR EVOLUTIONARY BIOLOGY 

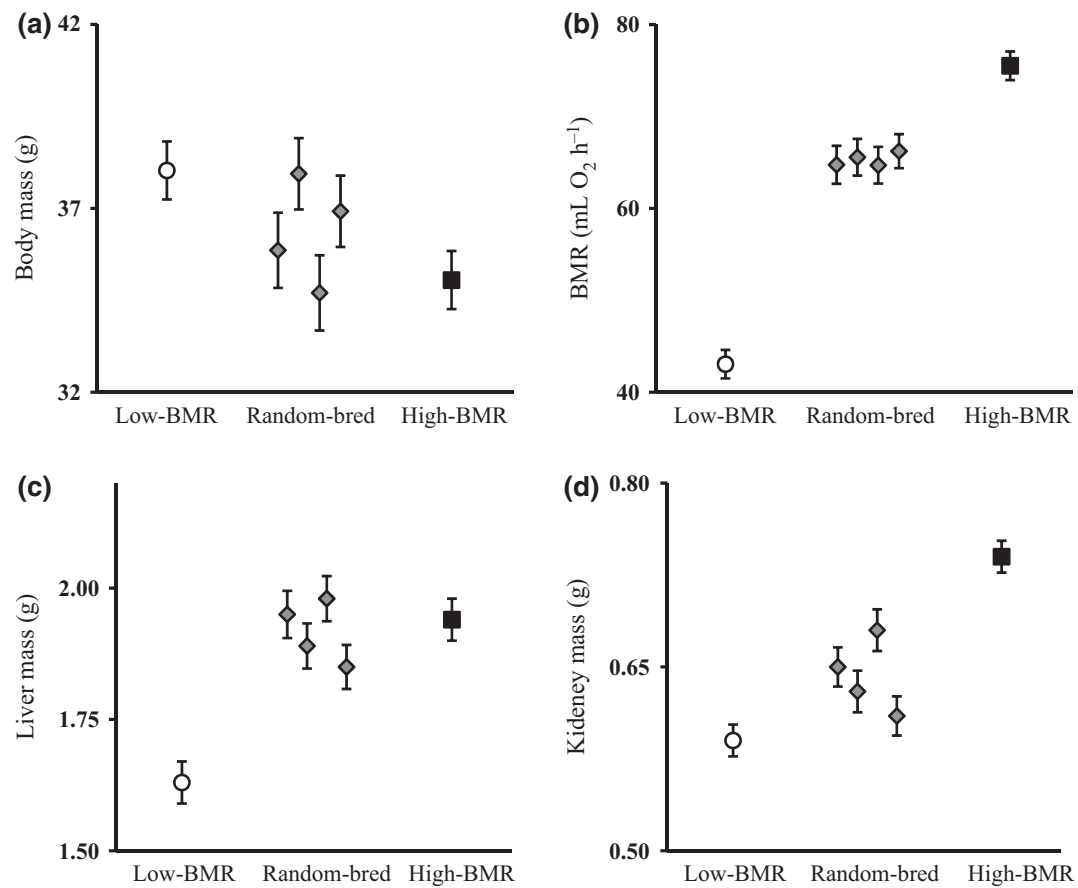

Fig. 1 Body mass (a), basal metabolic rate (BMR) (b), liver mass (c) and kidney mass (d) in lines of laboratory mice divergently selected for high BMR (black squares), low BMR (open circles, $N=15$ in both cases) and in four random-bred lines (grey diamonds, $N=40$ ). Graphs b-d show body mass adjusted means with standard errors, calculated from general linear models.

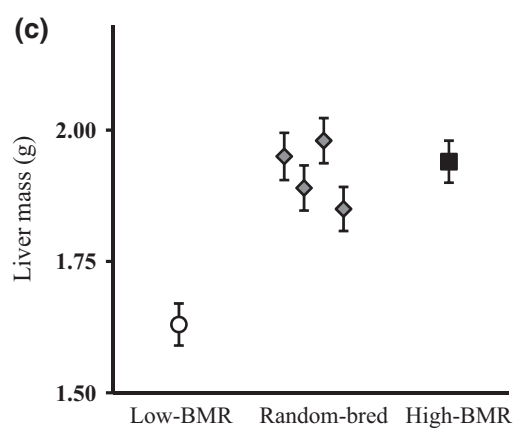

latter two groups did not differ in hepatocytes' karyoplasmic ratio. The karyoplasmic ratio of other cell types did not differ significantly between the lines of mice.

\section{Discussion}

Our results are in agreement with the data of earlier studies demonstrating that artificial divergent selection on body mass-corrected BMR not only resulted in sizable differences in the primary target trait, but also in a correlated divergence in mass of metabolically active organs (for review see Konarzewski \& Książek, 2013). Here, we showed for the first time that this selection affected size of the cells building these organs (see Fig. 3), as well as cells of other tissues involved in metabolism, such as erythrocytes. Furthermore, the magnitude of between-line divergence in cells size was large enough to claim that they arose due to applied selection rather than genetic drift: all values of separation coefficient $d_{x}$ fell outside an upper limit of $95 \%$ confidence intervals for $d_{\text {drift }}$ (Table 1), which supports a prevailing effect of selection in differentiation of these traits between high-BMR and low-BMR mice. This suggests that changes in cell size are inherently linked to the evolution of BMR.

The above findings, however, by themselves do not demonstrate the relative contribution of the variation in cell sizes and internal organ masses to the observed within-species variation in BMR, as exemplified by the six lines of mice compared in our study. If the cell metabolism hypothesis strictly holds, one would expect that random-bred mice having an intermediate BMR should also have intermediate size of cells. Our results, however, only partially agree with this expectation. Although our high-BMR mice were characterized by smaller size of erythrocytes and skin cells than randombred mice and low-BMR mice, the size of these cells did not differ between the low-BMR and random-bred mice. Apparently, the attainment of low BMR involved other pathways than an increase in BMR. Such asymmetry is also evident in other cell types as well as in organ masses. Compared with other lines, the lowBMR mice had smaller kidneys and livers. Metabolism of those organs in mammals accounted for as much as $30 \%$ of the whole-body resting metabolic rate (Rolfe $\delta$ Brown, 1997). Therefore, differences in the mass of these metabolically active organs are a likely explanation of the divergence of BMR in our mice. Our results, however, do not allow for disentangling the relative contribution of the size of those organs from the size of their cells on BMR. Nevertheless, the observed patterns suggest that large size of kidneys and liver of the $\mathrm{H}$ BMR mice was at least partially achieved through an increase in cell size (Fig. 3). It also remains to be seen whether this mechanism accounts for an exceptionally high heart mass of H-BMR line among laboratory mice subjected to different selection regimens (Fig. 4 in Gębczyński \& Konarzewski, 2011). Overall, our results are complementary to those of other artificial selection experiments, which showed that laboratory mice from lines selected for traits related to high metabolic rates have larger sizes of the internal organs compared with 

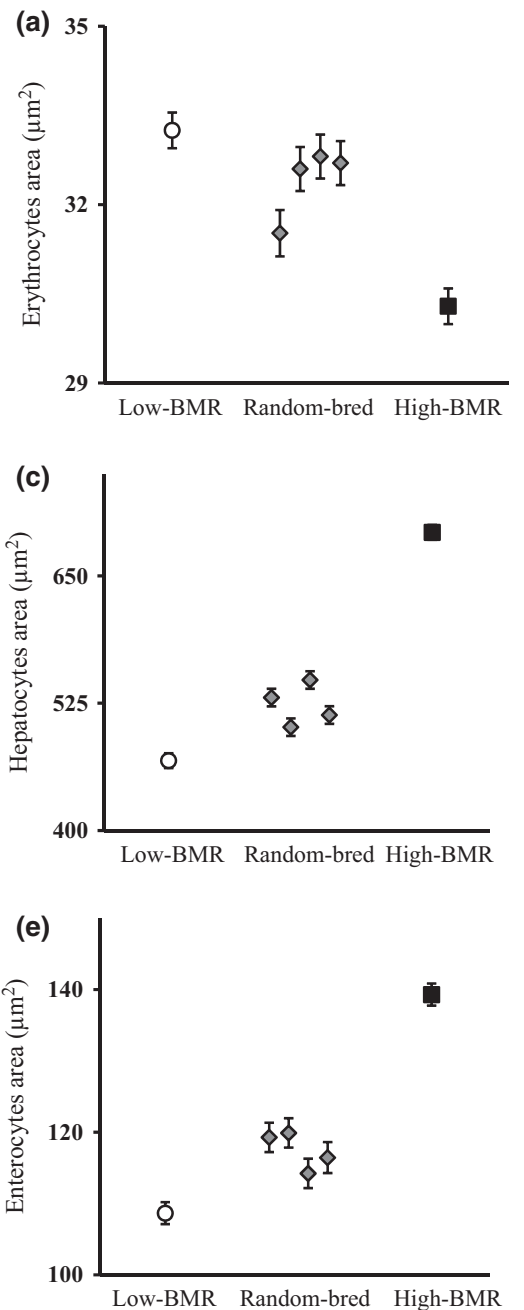
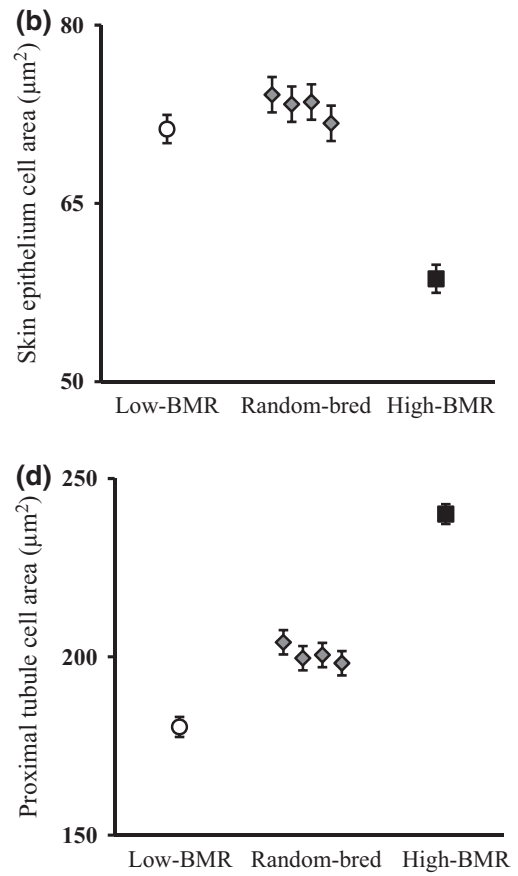

Table 2 Correlation analysis of sizes of cells and nuclei in five tissues of mice, conducted on mean line-specific values $(N=6$; one line of high-BMR mice, one line of low-BMR mice, and four lines of random-bred mice).

\begin{tabular}{|c|c|c|c|c|c|}
\hline & Erythrocytes & Hepatocytes & Kidney proximal tubule cells & Duodenum enterocytes & Nucleus \\
\hline Hepatocytes & $\begin{array}{l}-0.87 \\
P=0.02\end{array}$ & & & & $\begin{array}{l}0.99 \\
P<0.001\end{array}$ \\
\hline Kidney proximal tubule cells & $\begin{array}{l}-0.92 \\
P=0.01\end{array}$ & $\begin{array}{l}0.98 \\
P=0.001\end{array}$ & & & $\begin{array}{l}0.99 \\
P<0.001\end{array}$ \\
\hline Duodenum enterocytes & $\begin{array}{l}-0.91 \\
P=0.01\end{array}$ & $\begin{array}{l}0.93 \\
P=0.007\end{array}$ & $\begin{array}{l}0.98 \\
P=0.001\end{array}$ & & $\begin{array}{l}0.97 \\
P=0.002\end{array}$ \\
\hline Skin epithelium cells & $\begin{array}{l}0.74 \\
P=0.09\end{array}$ & $\begin{array}{l}-0.88 \\
P=0.02\end{array}$ & $\begin{array}{l}-0.85 \\
P=0.03\end{array}$ & $\begin{array}{l}-0.88 \\
P=0.02\end{array}$ & $\begin{array}{l}0.98 \\
P<0.001\end{array}$ \\
\hline
\end{tabular}

mice from lines selected for low rate of energy turnover (for review see Swallow et al., 2009).

Between-line variation in erythrocyte size observed therein deserves special attention, as one can expect a particularly close link between erythrocyte size, its function and BMR. Given the central role of erythrocytes in $\mathrm{O}_{2}$ transport, the observed change in their size and number suggests that high-BMR mice evolved
Fig. 2 Size of erythrocytes (a), skin epithelium cells (b), hepatocytes (c), kidney proximal tubule cells (d) and duodenum enterocytes (e), in lines of laboratory mice divergently selected for high BMR (black squares) $(N=15$ in both cases), low BMR (open circles) and in four random-bred lines (grey diamonds, $N=40$ ). Graph shows body mass adjusted means with standard errors calculated from general linear models. higher capacity to deliver $\mathrm{O}_{2}$ to peripheral tissue. There is evidence to demonstrate that an effective exchange of $\mathrm{O}_{2}$ in capillaries requires a short axis of an erythrocyte to be about $25 \%$ larger than a capillary diameter (Snyder \& Sheafor, 1999). Therefore, the size reduction in erythrocytes in high-BMR mice is also suggestive of concomitant changes in the vascular architecture of these mice. Collectively, our results suggest cellular and 

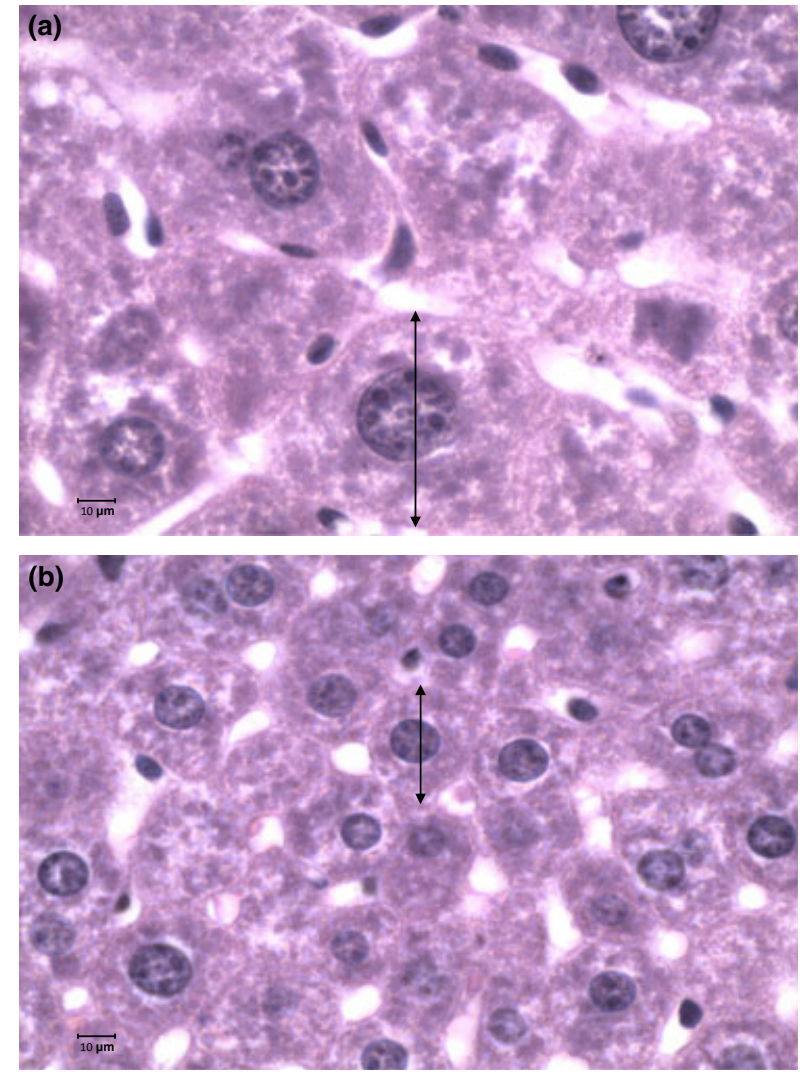

Fig. 3 Representative photomicrographs of hepatocytes and nuclei (magnification $1000 \times$ ) in the mice selected for high (a) and low (b) BMR. Arrows indicate cell diameters.

vascular mechanisms that evolved in high-BMR mice, increasing oxidative capacity in this group. Consistent with this idea, Gębczyński \& Konarzewski (2011) observed that high-BMR mice had higher peak metabolic rates during running at hypoxia than low-BMR and random-bred mice.

Large cells in livers, kidneys and duodenum of highBMR mice, and small cells in these organs of low-BMR mice do not support the concept of $\mathrm{CMH}$. This raises the question about how a change in the size of these cell types might translate into a change in the rate of metabolism. Liver and gastrointestinal tract cells of a rat in a standard metabolic state may devote about $24 \%$ and $74 \%$ of their $\mathrm{O}_{2}$ consumption to protein synthesis (Rolfe \& Brown, 1997), and much of this activity serves the other cells in the body as well. The costs of service functions of all cells in an organism are estimated to constitute between 25 and $50 \%$ of the standard metabolic rate (Rolfe \& Brown, 1997). Given the supracellular function of cells in livers, kidneys and duodenum, it is likely that mice evolved their BMR in tight association with shifts in the physiological service activity of these cells, and our data suggest that this activity might be linked to cell size and nucleus size.
Service functions involve a breakdown, synthesis and excretion of molecules, and this activity requires rapid transcription and translation. There is an agreement that the intensity of transcription and translation depends on the density of specific macromolecules in the nucleus and cytoplasm (Zimmerman, 1993; Ellis, 2001). Molecular crowding increases thermodynamic activities of protein synthesis machinery, but on the other hand it decreases diffusion of molecules within the cells. We propose that small cells may not be able to perform their service activity to the same degree as large cells, because biochemical reactions conducted in their small-volume cytoplasm are more prone to the dumping effect of molecular crowding. This would explain why we observed a positive association between BMR and the size of cells in organs involved in supracellular service activity. There is evidence to demonstrate that a large volume of cytoplasm requires increased rates of protein synthesis and specific genes expression (Marguerat \& Bahler, 2012). An example comes from Carvalhal et al. (2003) in vitro experiments on cell cultures. Cells that were manipulated to grow larger had an increased synthesis of proteins and ATP, and an increased consumption of $\mathrm{O}_{2}$ and glucose.

The increase in translational and transcriptional activity required by larger cells was suggested to be facilitated by larger nuclei (Webster et al., 2009). In support, a positive link between cell size, nucleus size and the rate of RNA transcription was reported (Schmidt \& Schibler, 1995). Our data are also consistent with this idea. First, we found that nucleus size and cell size in tissues of mice were positively correlated. Second, the karyoplasmic ratio in most of these tissues did not change in association with BMR, which indicates that changes in cellular volume in these tissues were followed by a proportional change in nuclear volume. Similarly, Neumann \& Nurse (2007) reported that nuclear size was proportional to cell size in fission yeast ranged over a 35-fold cell size variation. Interestingly, the karyoplasmic ratio of hepatocytes decreased its value in low-BMR mice, which indicates that low-BMR mice had hepatocytes with relatively small size of nuclei. This suggests a low transcriptional activity of a genome in these cells and agrees with the idea that the size of a nucleus matches physiological activity of a cell. An invariance of karyoplasmic ratio has long been regarded as a major puzzle in cell biology (CavalierSmith, 2005). Although mechanisms that control this cellular characteristic are still unclear (Cohen-Fix, 2010), our results support the view that this invariance might result from tuning of transcriptional activity to the intensity of physiological processes in cytoplasm.

Overall, it is becoming increasingly apparent that cell size cannot be ignored in studies of the evolution of metabolic rates. Emerging evidence shows that the rate of metabolism evolves in concert with cell size, and this coevolution is either coupled with evolutionary changes 
in body mass (Wheatley, 2007) or, as shown by our results and Maciak et al. (2011), it can proceed independently of body mass. Much of this evidence shows a negative association between mass-specific metabolic rates and cell size, which complies with the concept of $\mathrm{CMH}$. The crucial insight from our work is that better understanding of the coupling between the evolution of metabolic rates and cell size may require consideration of a different supracellular function and physiological activity (mainly catalytic) of cells. We envisage that the evolution of high metabolic rates might involve (i) reduction in cell size in the specialized tissues whose functions are primarily dictated by surfaceto-volume ratios, such as erythrocytes; and/or (ii) the increase in cell size and thus increased intensity of translation and transcription, in the tissue with high physiological activity.

\section{Acknowledgments}

This study was supported by Polish Ministry of Science and Higher Education grant N304 390638 in 20102012 as a research project. None of co-authors have a conflict of interest to declare.

\section{References}

Brown, J.H., Gillooly, J.F., Allen, A.P., Savage, V.M. \& West, G.B. 2004. Toward metabolic theory of ecology. Ecology 85: 1771-1789.

Brzęk, P., Bielawska, K., Książek, A. \& Konarzewski, M. 2007. Anatomic and molecular correlates of divergent selection for basal metabolic rate in laboratory mice. Physiol. Biochem. Zool. 80: 401-499.

Buttgereit, F. \& Brand, M.D. 1995. A hierarchy of ATP-consuming processes in mammalian cells. Biochem. J. 312: 163-167.

Carvalhal, A.V., Marcelino, I. \& Carrondo, M.J.T. 2003. Metabolic changes during cell growth inhibition by p27 overexpression. Appl. Microbiol. Biotechnol. 63: 164-173.

Cavalier-Smith, T. 2005. Economy, speed and size matter: evolutionary forces driving nuclear genome miniaturization and expansion. Ann. Bot. 95: 147-175.

Chown, S.L., Marais, E., Terblanche, J.S., Klok, C.J., Lighton, J.R.B. \& Blackburn, T.M. 2007. Scaling of insect metabolic rate is inconsistent with the nutrient supply network model. Funct. Ecol. 21: 282-290.

Cohen-Fix, O. 2010. Cell biology: import and nuclear size. Nature 468: 513-516.

Czarnołęski, M., Kozłowski, J., Dumiot, G., Bonnet, J.-C., Mallard, J. \& Dupont-Nivet, M. 2008. Scaling of metabolism in Helix aspersa snails: changes through ontogeny and response to selection for increased size. J. Exp. Biol. 211: 391-399.

Ellis, R.J. 2001. Macromolecular crowding: obvious but underappreciated. Trends Biochem. Sci. 26: 597-604.

Falconer, D.S. \& Mackay, T.F.C. 1996. Introduction to Quantitative Genetics, 4th edn. Longman, Essex.

Falconer, D.S., Gauld, I.K. \& Roberts, R.C. 1978. Cell numbers and cell sizes in organs of mice selected for large and small body size. Genet. Res. 31: 287-301.
Gębczyński, A. \& Konarzewski, M. 2009. Metabolic correlates of selection on aerobic capacity in laboratory mice: a test of the model for the evolution of endothermy. J. Exp. Biol. 212: 2872-2878.

Gębczyński, A. \& Konarzewski, M. 2011. Effects of oxygen availability on maximum aerobic performance in Mus musculus selected for basal metabolic rate or aerobic capacity. J. Exp. Biol. 214: 1714-1720.

Glazier, D.S. 2005. Beyond the '3/4-Power Law': variation in the intra- and interspecific scaling of metabolic rate in animals. Biol. Rev. 80: 611-662.

Glazier, D.S. 2010. A unifying explanation for diverse metabolic scaling in animals and plants. Biol. Rev. 85: 111-138.

Gregory, T.R. 2001. The bigger the c-value, the larger the cell: genome size and red blood cell size in vertebrates. Blood Cells Mol. Dis. 27: 830-843.

Harvey, P.H. \& Pagel, M.D. 1991. The comparative method in evolutionary biology. Oxford University Press, Oxford.

Henderson, N.D. 1997. Spurious associations in unreplicated selected lines. Behav. Genet. 27: 145-154.

Heusner, A.A. 1982. Energy metabolism and body size. Is the 0.75 mass exponent of Kleiber's equation a statistical artifact? Respir. Physiol. 48: 1-12.

Hochachka, P.W., Darveau, C.A., Andrews, R.D. \& Suarez, R.K. 2003. Allometric cascade: a model for resolving body mass effects on metabolism. Comp. Biochem. Physiol. A. Mol. Integr. Physiol. 134: 675-691.

Isaac, N.J.B. \& Carbone, C. 2010. Why are metabolic scaling exponents so controversial? Quantifying variance and testing hypotheses. Ecol. Lett. 13: 728-735.

Jones, D.L., Nielsen, M.K. \& Britton, R.A. 1992. Genetic variation in liver mass, body mass, and liver: body mass in mice. J. Anim. Sci. 70: 2999-3006.

Jorgensen, P. \& Tyers, M. 2004. How cells coordinate growth and division. Curr. Biol. 14: 1014-1027.

Kleiber, M. 1947. Body size and metabolic rate. Physiol. Rev. 27: $511-541$.

Koch, L.G. \& Britton, S.L. 2001. Artificial selection for intrinsic aerobic endurance running capacity in rats. Physiol. Genomics 5: $45-52$.

Konarzewski, M. \& Książek, A. 2013. Determinants of intra-specific variation in basal metabolic rate. J. Comp. Physiol. 183: 27-41.

Konarzewski, M., Książek, A. \& Łapo, I.B. 2005. Artificial selection on metabolic rates and related traits in rodents. Integr. Comp. Biol. 45: 416-425.

Kooijman, S.A.L.M. 2010. Dynamic Energy Budget Theory for Metabolic Organisation, pp. 532. Cambridge University Press, Cambridge.

Kozłowski, J., Konarzewski, M. \& Gawelczyk, A.T. 2003. Cell size as a link between noncoding DNA and metabolic rate scaling. PNAS 24: 14080-14085.

Kozłowski, J., Czarnołęski, M., Francois-Krassowska, A., Maciak, S. \& Pis, T. 2010. Cell size is positively correlated between different tissues in passerine birds and amphibians, but not necessarily in mammals. Biol. Lett. 6: 792-796.

Książek, A., Konarzewski, M. \& Łapo, I.B. 2004. Anatomic and energetic correlates of divergent selection for basal metabolic rate in laboratory mice. Physiol. Biochem. Zool. 77: 890-899.

Maciak, S., Janko, K., Kotusz, J., Choleva, L., Boroń, A., Juchno, D. et al. 2011. Standard Metabolic Rate (SMR) is 
inversely related to erythrocyte and genome size in allopolyploid fish of the Cobitis taenia hybrid complex. Funct. Ecol. 25: 1072-1078.

Makarieva, A.M., Gorshkov, V.G., Li, B.-L., Chown, S.L., Reich, P.B. \& Gavrilov, V.M. 2008. Mean mass-specific metabolic rates are strikingly similar across life's major domains: evidence for life's metabolic optimum. PNAS 105: 16994-16999.

Marguerat, S. \& Bahler, J. 2012. Coordinating genome expression with cell size. Trends Genet. 28: 560-565.

McNab, B.K. 2008. An analysis of the factors that influence the level and scaling of mammalian BMR. Comp. Biochem. Physiol. A. Mol. Integr. Physiol. 151: 5-28.

Neumann, F.R. \& Nurse, P. 2007. Nuclear size control in fission yeast. J. Cell Biol. 179: 593-600.

Rolfe, D.F. \& Brown, G.C. 1997. Cellular energy utilization and molecular origin of standard metabolic rate in mammals. Physiol. Rev. 77: 731-758.

Schlager, G. 1968. Kidney weight in mice: strain differences and genetic determination. J. Hered. 59: 171-174.

Schmidt, E.E. \& Schibler, U. 1995. Cell size regulation, a mechanism controls cellular RNA accumulation: consequences on regulation of the ubiquitous transcription factors Octl and NF-Y, and the liver-enriched transcription factor DBP. J. Cell Biol. 128: 467-483.

Snyder, G.K. \& Sheafor, B.A. 1999. Red blood cells: centerpiece in the evolution of the vertebrate circulatory system. Am. Zool. 39: 189-198.

Starostová, Z., Konarzewski, M., Kozłowski, J. \& Kratochvíl, L. 2013. Ontogeny of metabolic rate and red blood cell size in Eyelid geckos: species follow different paths. PLOS ONE 8: e64715.

Stevenson, R.D., Hill, M.F. \& Bryant, P.J. 1995. Organ and cell allometry in Hawaiian Drosophila: how to make a big fly. Proc. Biol. Sci. 259: 105-110.
Swallow, J.G., Hayes, J.P., Koteja, P. \& Garland, T. Jr 2009. Selection experiments and experimental evolution of performance and physiology. In: Experimental Evolution: Concepts, Methods, and Applications of Selection Experiments (T. Garland Jr, M.R. Rose, eds), pp. 301-351. University of California Press, Berkeley, CA.

Webster, M., Witkin, K.L. \& Cohen-Fix, O. 2009. Sizing up the nucleus: nuclear shape, size and nuclear-envelope assembly. J. Cell Sci. 122: 1477-1486.

Wells, W.A. 2002. Does size matter? J. Cell Biol. 158: 1156-1159.

Wheatley, D.N. 2007. Convergence of metabolic rate of cultured cells from animals of different sizes. Am. J. Physiol. Regul. Integr. Comp. Physiol. 292: R2113-R2114.

White, C.R., Cassey, P. \& Blackburn, T.M. 2007. Allometric exponents do not support a universal metabolic allometry. Ecology 88: 315-323.

White, C.R., Kearney, M.R., Matthews, P.G.D., Kooijman, S.A.L.M. \& Marshall, D.J. 2011. A manipulative test of competing theories for metabolic scaling. Am. Nat. 178: 746-754.

Wislöff, U., Najjar, S.M., Ellingsen, R., Haram, P.M., Swoap, S., Al-Share, Q. et al. 2005. Cardiovascular risk factors emerge after artificial selection for low aerobic capacity. Science 307: 418-420.

Withers, P.C. 1977. Measurement of $\mathrm{VO}_{2}, \mathrm{VCO}_{2}$ and evaporative water loss with a flow through mask. J. Appl. Physiol. 42: 120-123.

Zimmerman, S.B. 1993. Macromolecular crowding effects on macromolecular interactions: some implications for genome structure and function. Biochim. Biophys. Acta 1216: $175-185$.

Received 17 October 2013; accepted 19 November 2013 